$21^{\text {st }}$ INTERNATIONAL DEPENDENCY AND STRUCTURE MODELING CONFERENCE, DSM 2019

MONTEREY, CA, USA, 23 - 25 September, 2019

\title{
Development of a Product Platform for Ship Locks Using DSM Methods
}

\author{
S.C.M. Knippenberg ${ }^{1}$, L.F.P. Etman ${ }^{1}$, J.E. Rooda ${ }^{1}$, E.J. Houwing ${ }^{2}$, J.A. Vogel ${ }^{2}$ \\ ${ }^{1}$ Eindhoven University of Technology, $5600 \mathrm{MB}$, Eindhoven, The Netherlands \\ ${ }^{2}$ Rijkswaterstaat, 3526 LA, Utrecht, The Netherlands
}

\begin{abstract}
During the coming decades, a significant number of ship locks in the Netherlands is due for replacement or renovation. In this respect, Rijkswaterstaat (RWS), the executive branch of the Dutch Ministry of Infrastructure and Water Management, is investigating the options while allowing for the necessary variety in lock configurations to meet lock location specific requirements. This paper presents the development of a product platform for locks to standardize selected lock components and to reduce the level of variety within the portfolio. Considering components and parameters, that are the main determinants in civil-mechanic lock design, the required solution freedom in choosing component types is determined to arrive at feasible lock configurations. Feasible configurations are determined for the locks in the RWS portfolio. A component and design process DSM analysis is carried out to arrive at a decision sequence for selecting component types to configure a lock. Keywords: Ship locks, Standardization, Product platform, Component DSM, Precedence DSM
\end{abstract}

\section{Introduction}

Ship locks are essential for waterborne transportation in the Dutch infrastructure. They regulate differences in water level and facilitate the passage of ships between waterways with different water levels. When a ship has entered the lock chamber via the gate on one side of the lock, the water level is raised or lowered. Next, the gate on the other side of the lock will open and the ship can continue its way. In the Netherlands, a significant number of locks have been built in the first half of the twentieth century. Many of these are now due for renovation. So far, the prevalent lock realization strategy has been Engineer-toOrder. As a result, there is currently a large variety in the designs of the many locks in the Netherlands (Wilschut et al., 2019). Most locks have a unique configuration of for example the type of gate, the type of water leveling system, and the type of gate actuators, meeting the location specific requirements and constraints.

Rijkswaterstaat (RWS), the executive branch of the Dutch Ministry of Infrastructure and Water Management, is responsible for the design, construction, management, and maintenance of locks in the main waterways in the Netherlands. RWS has investigated their lock portfolio and concludes that quite a number of locks will reach the end of their predicted technical lifetime in the coming years. Furthermore, several locks do not meet modern-day (safety) standards, or the capacity to transfer ships becomes insufficient, given the projected growth of waterborne transportation. To support the planned renovation and construction in the coming decades, RWS has founded the MultiWaterWerk (MWW) 


\section{Part V: Use Cases}

project. The goal of this project is to modularize and (partially) standardize lock components seeking to accommodate the serial renovation process (two or three locks per year), to improve maintainability, and to reduce life cycle costs of the locks in the portfolio. The number of locks to be renovated and constructed gives the opportunity to reconsider the existing preferences for lock configurations and to investigate options to develop a product platform for design and renovation of locks.

In the literature, various definitions of a product platform are presented. Pahl and Beitz (2007) describe the development of a product platform as a method to define commonalities within the product portfolio consisting of variant rich products. Similar definitions mentioning the collection of common elements shared in multiple products are given by McGrath (2000), Simpson and Souza (2004), and Ulrich and Eppinger (2015). The following definition by Meyer and Lehnerd (2011, p.7) neatly aligns with the aforementioned MWW goal of RWS: "A product platform is a set of common components, modules, or parts from which a stream of derivative products can be efficiently created and launched." According to Meyer and Lehnerd (2011), the development of product families can assist in handling the increasing complexity of products and enables to reduce the costs of product development. According to Hölttä-Otto (2005), modular product platforms can result in the reduction of costs and in a quicker introduction of various product variants. According to Martin and Ishii (1996), life cycle costs of a product can be lowered by reducing the impact caused by the variety of the product portfolio.

Product platforms are widely used in different fields of industry. In 1909, during the production of the Ford Model T, Henry Ford stated: "Any customer can have a car painted any color that he wants so long as it is black" (Ford and Crowther, 1922, p.71). Nowadays, customers can customize their Ford car in more than 3.8 million different configurations (Simpson, 2005). This holds for nearly all other automotive manufacturers. For example Volkswagen, one of the global leaders in the car industry, applies only four platforms for the production of millions of passenger cars each year (Winter and Zoia, 2001). Next to the automotive sector, other industries apply product platforms for their range of products. Sony applied product platforms for the development of Walkman products to continuously introduce new models to the market (Sanderson and Uzumeri, 1995). Furthermore, the development team of Hewlett-Packard designed a product platform strategy for their range of home printing devices (Ulrich and Eppinger, 2015). Within the domain of the engineering of locks, the concept of a product platform for locks seems to be less wellknown.

This paper proposes a method to develop a product platform for ship locks using dependency structure matrix (DSM) methods (Eppinger and Browning, 2012). Departing from the outcome of the commonality analysis by Wilschut et al. (2019), components are selected that have a major influence on the performance and costs of civil-mechanic lock design. This is described in Section 2. Also, the dependencies between these components are elaborated here. These dependencies are visualized using a product DSM. Section 3 outlines which types (e.g. type of gates) are feasible for each of the selected components. Next, Section 4 uses a sequenced process DSM to find the best order to make component configuration choices, thus minimizing feedback. In Section 5, a similarity matrix analysis (Chen and Li, 2005; Wilschut et al., 2019) is executed for 127 lock locations in the portfolio of RWS to develop a basic lock platform. Finally, conclusions are presented in Section 6 . 


\section{Lock components}

The first steps in transforming the current lock portfolio into a lock product platform are described in this section. In their commonality analysis, Wilschut et al. (2019) considered 72 elements in the lock decomposition and clustered these into ten main modules. Their analysis presents the common and the optional modules, the basic product structure, and the modules that have the highest impact on reliability and on life cycle costs, given the characteristics of the existing locks in the RWS portfolio. With the forthcoming lock renovations, this gives the opportunity to reconsider lock configurations. This paper derives the minimum set of lock configuration families that present feasible solutions for all locks.

We start the development of the lock platform by selecting twelve components (out of the previously mentioned 72 elements), whose configuration choice is known to have a major influence on system performance and on configuration choices for the other components. The lock construction principles presented in Josephus Jitta (1947) and Glerum and Vrijburcht (2000) are used as a guideline. Together, these components fulfill the main functions of a ship lock: regulating differences in water level and providing ship passage between two waterways of different water levels. Table 1 gives an overview of the twelve components with their function.

Table 1: Twelve components for civil-mechanic lock design with their function.

\begin{tabular}{|l|l|l|}
\hline ID & \multicolumn{1}{|c|}{ Component } & \multicolumn{1}{c|}{ Function } \\
\hline 1 & Leading jetty & $\begin{array}{l}\text { Guiding ships into the lock chamber, without } \\
\text { causing damage to the lock. }\end{array}$ \\
\hline 2 & Leveling system & $\begin{array}{l}\text { Leveling water inside the lock chamber, to } \\
\text { correspond to the water level outside the lock. }\end{array}$ \\
\hline 3 & Gates & $\begin{array}{l}\text { Retaining water during water leveling when } \\
\text { closed and allowing ships to when open. }\end{array}$ \\
\hline 4 & Gate actuators & Facilitating the opening and closing of gates. \\
\hline 5 & $\begin{array}{l}\text { Leveling system } \\
\text { actuators }\end{array}$ & $\begin{array}{l}\text { Facilitating the opening and closing of lock } \\
\text { gates of the leveling system. }\end{array}$ \\
\hline 6 & Lock heads & $\begin{array}{l}\text { Providing support, turning points, and guides } \\
\text { for gates and gate actuators. }\end{array}$ \\
\hline 7 & Lock chamber & $\begin{array}{l}\text { Isolating a part of the waterway, in which ships } \\
\text { can be raised or lowered. }\end{array}$ \\
\hline 8 & Seepage screens & $\begin{array}{l}\text { Preventing water to flow through the soil } \\
\text { outside the lock, causing instabilities in the } \\
\text { construction of a lock. }\end{array}$ \\
\hline 9 & $\begin{array}{l}\text { Ice prevention } \\
\text { system }\end{array}$ & $\begin{array}{l}\text { Preventing ice to hinder gates, actuators, and } \\
\text { passing ships. }\end{array}$ \\
\hline
\end{tabular}

The dependencies between the components are represented in a grouped, bi-directional component DSM, the blue part of Figure 1. A mark in this DSM can represent a physical connection, an information flow, a material flow, and/or an energy flow (Eppinger and Browning, 2012). 
Table 1 (ctd.): Twelve components for civil-mechanic lock design with their function.

\begin{tabular}{|c|l|l|}
\hline ID & \multicolumn{1}{|c|}{ Component } & \multicolumn{1}{c|}{ Function } \\
\hline 10 & Soil protection & $\begin{array}{l}\text { Protecting the soil outside the lock for propeller } \\
\text { turbulences or for the outflow of water. }\end{array}$ \\
\hline 11 & $\begin{array}{l}\text { Salt/fresh water } \\
\text { separation system }\end{array}$ & $\begin{array}{l}\text { Separating fresh and salt water between the } \\
\text { waterways separated by a lock. }\end{array}$ \\
\hline 12 & $\begin{array}{l}\text { Supervisory control } \\
\text { system }\end{array}$ & $\begin{array}{l}\text { Controlling the components of a lock to ensure } \\
\text { correct and safe dynamic behavior. }\end{array}$ \\
\hline
\end{tabular}

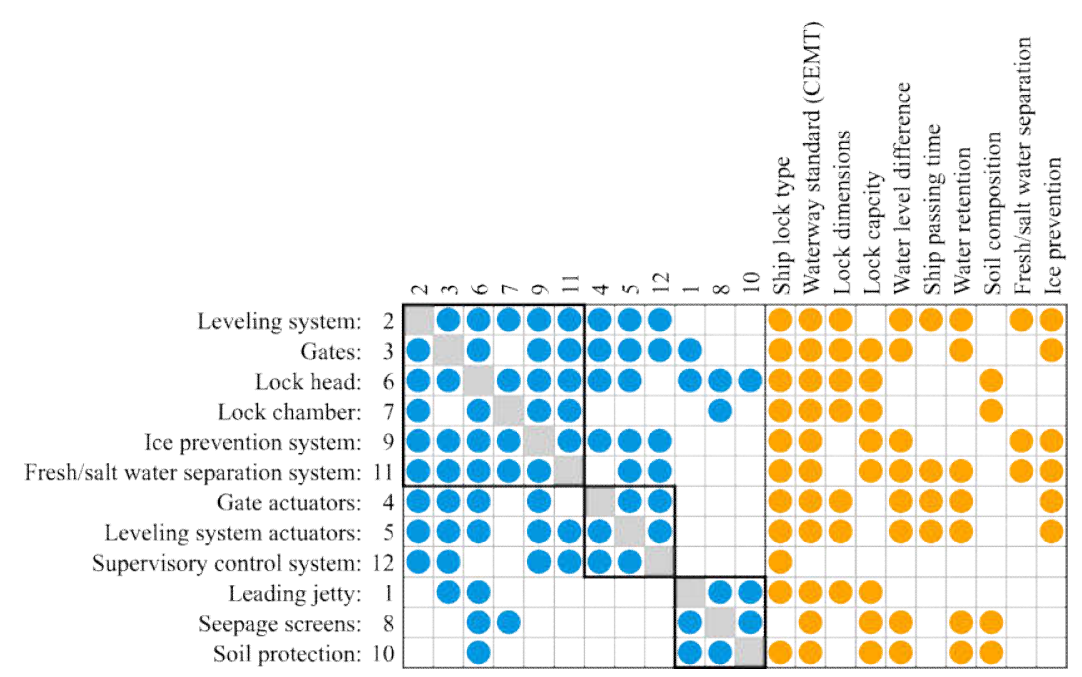

Figure 1: Multi-domain matrix visualizing the grouped component DSM of the components of a lock (blue), and the mapping of parameters (Section 3) to the components (orange).

From Figure 1, three groups of components can be identified. These groups were derived by manually joining components that together fulfil a lock function, i.e., the damming of water or the actuation of components:

1. Group with waterway components inside the lock: (2), (3), (6), (7), (9), and (11). This group can be identified as a bus since the components are interlinked with most of the other components in the other groups.

2. Group with the actuating components and the supervisory control system: (4), (5), and (12).

3. Group with waterway components outside the lock: (1), (8), and (10).

In the next section, the feasible type choices for the twelve components are determined (e.g. type of gates). 
S.C.M. Knippenberg, L.F.P. Etman, J.E. Rooda, E.J. Houwing, J.A. Vogel

\section{Component types}

To evaluate which component types are feasible for each of the components, considering their mutual interdependencies, a selection of parameters is used. These parameters are selected in accordance with Josephus Jitta (1947) and Glerum and Vrijburcht (2000). They describe the parameters that need to be considered in lock design. Table 2 presents the ten parameters with a concise description.

Table 2: Ten parameters with a concise description.

\begin{tabular}{|l|l|}
\hline \multicolumn{1}{|c|}{ Parameter } & \multicolumn{1}{c|}{ Description } \\
\hline Lock type & Type of ship lock, e.g. navigation lock or sea lock. \\
\hline Waterway standard & $\begin{array}{l}\text { Classification of European Inland Waterways, defining } \\
\text { the range of dimensions from CEMT I to CEMT VII } \\
\text { (Glerum and Vrijburcht, 2000). }\end{array}$ \\
\hline Lock dimensions & $\begin{array}{l}\text { Dimensions of the lock and its surroundings, required to } \\
\text { build the lock. }\end{array}$ \\
\hline Lock capacity & $\begin{array}{l}\text { Number of vessels that can be leveled at once in the lock } \\
\text { chamber. }\end{array}$ \\
\hline $\begin{array}{l}\text { Water level } \\
\text { difference }\end{array}$ & $\begin{array}{l}\text { Maximum possible difference between the water levels } \\
\text { on both sides of the lock. }\end{array}$ \\
\hline Leveling time & Time it takes to level the water inside the lock chamber. \\
\hline Water retention & Retention of water, single or double water retention. \\
\hline Soil composition & Composition of the soil the lock is built on. \\
\hline $\begin{array}{l}\text { Fresh/salt water } \\
\text { separation }\end{array}$ & $\begin{array}{l}\text { Do the waterways on both sides of the lock contain } \\
\text { different types (fresh or salt) of water? I.e. is fresh/salt } \\
\text { water separation required? }\end{array}$ \\
\hline Ice prevention & $\begin{array}{l}\text { Do the lock components suffer from ice forming when the } \\
\text { water is freezing? I.e. is ice prevention required? }\end{array}$ \\
\hline
\end{tabular}

From the location specific values of the parameters listed in Table 2, the feasible solution types for the twelve components (Section 2) are derived. These component types are chosen according to a greenfield process, which does not include brownfield process related constraints (Lehtonen et al., 2011). The orange part of the multiple-domain matrix (MDM) of Figure 1 visualizes which parameters affect the type choice for which components. In this domain mapping matrix (DMM), it can also be noticed that the soil composition does not influence the group with the actuating components and the supervisory control system. Furthermore, the ship passage time, the fresh/salt water separation, and the ice prevention do not influence the group with waterway components outside the lock. All parameters affect the solution type selection of the components that are member of the group with waterway components inside the lock.

From the number of feasible solution types per component, a total of 369,360 lock configurations may be generated. Herein, the number of feasible types of the supervisory control system (12) is excluded since its type depends entirely on the type choices for the other components. 


\section{Part V: Use Cases}

An insightful visualization of the feasible solution types for each of the components is achieved by using Venn diagrams (Venn, 1881). A Venn diagram displays the feasible solution types of a particular component for all lock locations in the portfolio into a single view, as shown in Figure 2. Here, the feasible types for the 127 lock locations are presented for the leveling system as well as for the gates.
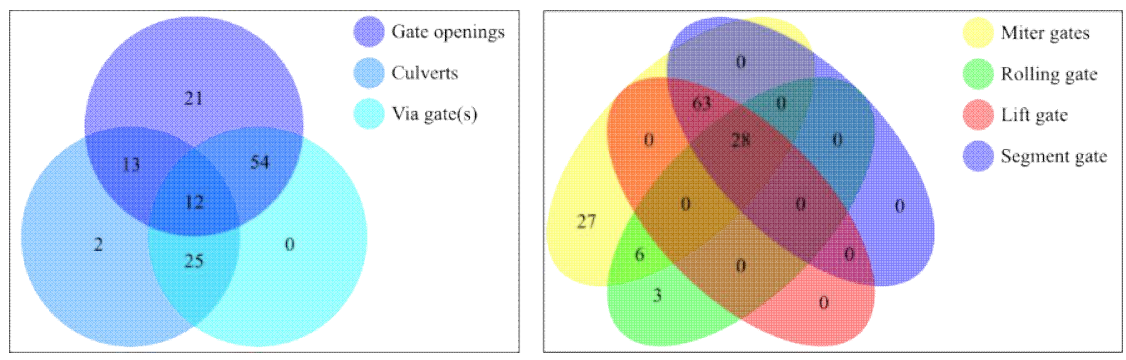

Figure 2: Venn diagram of the feasible solution types of the leveling system (left) and of the gates (right) for the 127 ship locks.

For three different leveling system solution types (gate openings, culverts, and via gates), the Venn diagram in the left of Figure 2 displays which solution types are feasible for how many locks out the considered 127 lock locations:

- 21 locks: Gate openings

- 2 locks: Culverts

- 13 locks: Gate openings or culverts

- 54 locks: Gate openings or via gate(s)

- 25 locks: Culverts or via gate(s)

- 12 locks: Gate openings, culverts, or via gate(s)

With gate openings and culverts, the entire set of 127 locks can be addressed. Similarly, the Venn diagram for the gates in Figure 2, shows that the following gate types are feasible:

- 27 locks: Miter gates

- 3 locks: Rolling gate

- 6 locks: Miter gates or rolling gate

- 63 locks: Miter gates, lift gate, or segment gate

- 28 locks: Miter gates, rolling gate, lift gate, or segment gate

For the gates, the minimum solution set that is able to cover all locks is miter gates and rolling gates.

\section{Precedence of selecting lock components}

In the next step, the precedence relations in selecting the types for the components are determined, accounting for the type choice dependencies between these components. That is, if a solution type choice for a particular component influences the type choice in another 
component. These dependencies are derived from Josephus Jitta (1947) and Glerum and Vrijburcht (2000). The directed Precedence DSM of Figure 3 displays these relations. This figure follows the input in rows convention. Sequencing (Eppinger and Browning, 2012; De Jong, 2019) is applied to seek for a feedforward sequence that minimizes the design iterations.

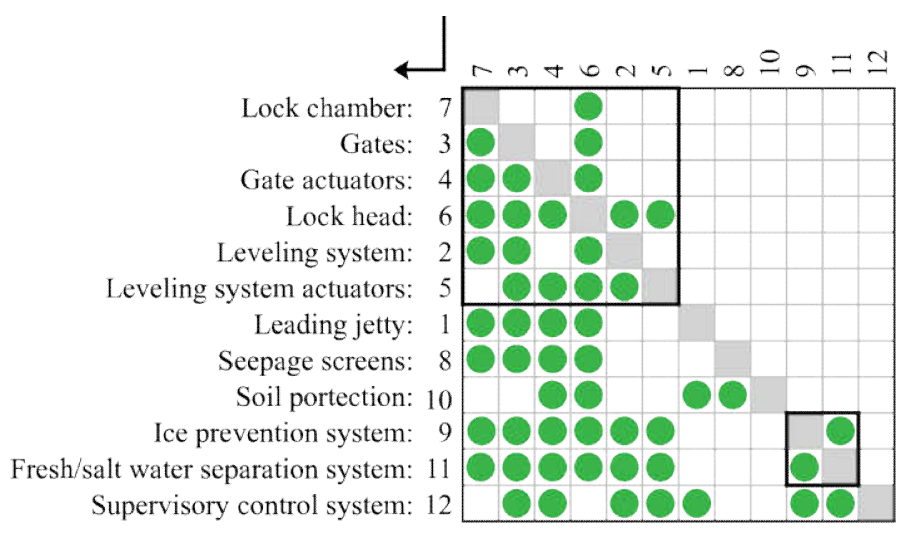

Figure 3: Sequenced precedence DSM of selecting component types, following the input in rows convention.

The precedence DSM in Figure 3 shows the precedence of selecting solution types for components. A mark denotes that a column element is an input for a row element. The dependencies above the diagonal imply that component choices may need to be reconsidered when choices later in the design sequence are made, resulting in possible rework. The sequencing is performed in such a way the amount of rework is minimized. Two clusters of coupled component type selections arise along the diagonal of the DSM:

1. A cluster consisting of the type selection of the lock chamber (7), the gates (3), the gate actuators (4), the lock head (6), leveling system (2), and the leveling system actuators (5).

2. A cluster consisting of the type selection of the ice prevention (9) and the fresh/salt water separation (11).

Figure 4 gives a directed graph view of the sequence of type selection of the components of a lock and possible iteration loops. Again, components are represented by their corresponding index number (see Table 1).

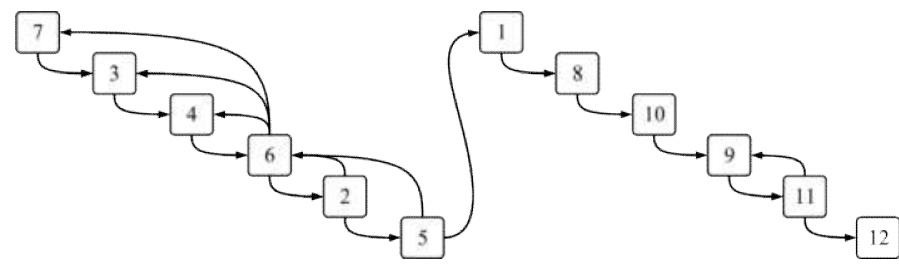

Figure 4: Directed graph representing the precedence of selecting component types. 


\section{Part V: Use Cases}

\section{Ship lock platform}

To reduce the number of possible lock configurations, feasible component types are selected based on the location-specific parameters for each lock. From this selection, a product platform is derived consisting of standardized components.

Specifically, the number of possible lock configurations is reduced by limiting the freedom of choice to the type of the gates and to the type of leveling system. Subsequently, each gate type is associated with one particular type of gate actuators, and each type of leveling system is associated with one particular type of leveling system actuators. Finally, the type choice for the remaining components is limited to one standard component. This leads to a lock platform consisting of five different lock configurations (families), as presented in the similarity matrix of Figure 5.

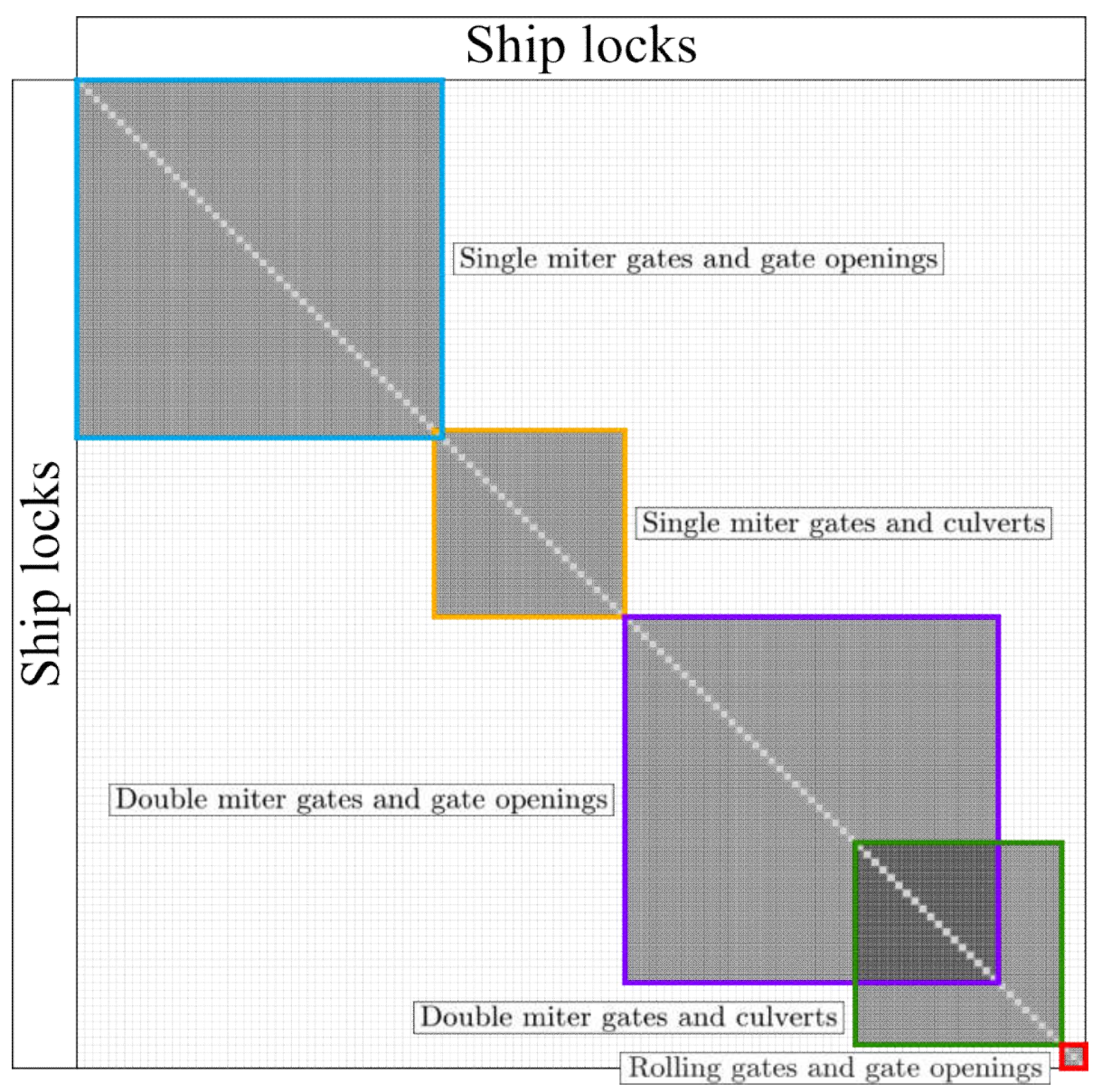

Figure 5: Similarity matrix in which locks are grouped for which the indicated configuration of gate type and leveling system type can be applied. 
S.C.M. Knippenberg, L.F.P. Etman, J.E. Rooda, E.J. Houwing, J.A. Vogel

The similarity matrix in Figure 5 groups together locks (displayed as elements on the axes of the figure) for which one particular configuration (gates and leveling system combination) can be used. By limiting the freedom in choice for each lock to just the configurations displayed in Figure 5, a lock product platform with a minimum number of variations can be obtained. In this platform, most locks are member of just one configuration family, while a few are member of two configuration families. For the former locks, there is one prescribed family configuration. For the latter locks, one can choose between two families. The five lock configurations are:

1. Single miter gates and gate openings

2. Single miter gates and culverts

3. Double miter gates and gate openings

4. Double miter gates and culverts

5. Rolling gate and gate openings

In this platform, there are three types of gates and two types of leveling systems, while a rolling gate choice implies gate openings.

\section{Conclusions}

This study presents the development of a product platform for locks by applying DSM methods to the lock portfolio of Rijkswaterstaat. The renovation of locks provides the opportunity to reconsider the current existing lock configurations and seek to reduce the variation in different components through the product platform. The study considers twelve components that are the main determinants for the structure of the civil-mechanic lock design. A product DSM of these components has been made and grouped. Three main groups of components arise. Based on lock construction guidelines and books, we selected ten parameters that are the main determinants for selecting solution types for the components. On this basis, feasible component solution types have been determined for each of the 127 locks. These solution types have been displayed used Venn diagrams. Furthermore, a mapping matrix has been added to map the parameters to the components.

To configure the civil-mechanic design of a lock, a sequence for selecting the component types has been derived by building a precedence DSM with dependencies between the solution choices of the components. Sequencing of this precedence DSM has been applied to minimize the distance of feedback matrix entries to the diagonal to reduce the rework. It is observed that the choice of the component types can be confined to just two components, the gates and the leveling system, while the solution type for the other components can be derived directly from choices for these two components, or a standard component solution may be chosen that works irrespective of the lock location. Then a similarity matrix is used to display the minimum set of lock configurations that covers all 127 locks. This basic product platform of the RWS lock portfolio in the Netherlands consists of five different lock configurations (families). In this platform, the freedom in 


\section{Part V: Use Cases}

choosing component types has been limited to two components and standardized types for the remaining ten components follow suit.

\section{Acknowledgments}

We thank Rijkswaterstaat, part of the Dutch Ministry of Infrastructure and Water Management, for the financial support for this research. In particular, we thank Maria Angenent, Wilco Meijerink, and Robert de Roos for their enthusiastic involvement in this project.

\section{References}

Chen, L., Li, S., 2005. Analysis of decomposability and complexity for design problems in the context of decomposition. Journal of Mechanical Design, 127(4), pp. 29-38.

Eppinger, S.D., Browning, T.R., 2012. Design structure matrix methods and applications. The MIT Press, Cambridge, MA.

Ford, H., Crowther, S., 1922. My life and work. Doubleday, Page and Company, Garden City, NY.

Glerum, A., Vrijburcht, A., 2000. Design of locks. Bouwdienst Rijkswaterstaat, Utrecht, The Netherlands.

Hölttä-Otto, K., 2005. Modular product platform design. Doctoral Thesis, Department of Mechanical Engineering, Helsinki University of Technology, Espoo, Finland.

Josephus Jitta, J.P., 1947. Sluizen en andere waterbouwkundige kunstwerken in en langs kanalen. De Erven F. Bohn N.V., Haarlem, The Netherlands. In Dutch.

De Jong, J.P., 2019. Exploration and implementation of sequencing algorithms for design structure matrices. Master's Thesis, CST 2019.027, Department of Mechanical Engineering, Eindhoven University of Technology, Eindhoven, The Netherlands.

Lehtonen, T., Pakkanen, J., Järvenpää, J., Lanz, M., Tuokko, R., 2011. Brownfield process for developing of product families. Proceedings of the 2011 International Conference on Engineering Design (ICED11), 15-18 August 2011, Copenhagen, Denmark, pp. 248-257.

Martin, M.V., Ishii, K., 1996. Design for variety: A methodology for understanding the costs of product proliferation? Proceedings of the 1996 ASME Design Engineering Technical Conferences and Computers in Engineering Conference, 18-22 August 1996, Irvine, CA.

McGrath, M.E., 2000. Product strategy for high-technology companies. McGraw-Hill Education Europe, Maidenhead, UK.

Meyer, M.H., Lehnerd, A.P., 2011. The power of product platforms: building value and cost leadership. The Free Press, New York, NY.

Pahl, G., Beitz, W., Feldhusen, J., Grote, K.H., 2007. Engineering design: A systematic approach. Springer-Verlag London, London, UK.

Sanderson, S., Uzumeri, M., 1992. Managing product families: the case of the Sony Walkman. Research Policy, 24(5), pp. 761-782.

Simpson, T.W., D’Souza, B.S., 2004. Assessing variable levels of platform commonality within a product family using a multiobjective genetic algorithm. Concurrent Engineering, 12(2), pp. 119-129.

Simpson, T.W., Siddique, Z., Jiao, J., 2005. Platform-based product family development. In: Product platform and product family design, pp. 1-15, Springer, New York, NY.

Ulrich, K., Eppinger, S.D., 2015. Product design and development. McGraw-Hill Education Europe, Maidenhead, UK.

Venn, J., 1881. Symbolic logic. Macmillan and Company, London, UK. 
S.C.M. Knippenberg, L.F.P. Etman, J.E. Rooda, E.J. Houwing, J.A. Vogel

Wilschut, T., Etman, L.F.P., Rooda, J.E., Vogel, J.A., 2019. Similarity, modularity, and commonality analysis of navigation locks in the Netherlands. Journal of Infrastructure Systems, 25(1): 04018043.

Winter, D., Zoia, D., 2001. Rethinking platform engineering. WARD's Auto World.

Contact: S.C.M. Knippenberg, Eindhoven University of Technology, Department of Mechanical Engineering, PO Box 513, 5600 MB Eindhoven, The Netherlands, s.c.m.knippenberg@tue.nl 